\title{
Germinação in vitro de Hyptis leucocephala Mart. ex Benth. e Hyptis platanifolia Mart. ex Benth.
}

NEPOMUCENO, C.F.1,2* FONSECA, P.T.'; SILVA, T.S.'; OLIVEIRA, L.M.'; SANTANA, J.R.F. ${ }^{1}$ Universidade Estadual de Feira de Santana (UEFS) - Laboratório de Cultura de Tecidos Vegetais, Horto Florestal. 44031-460: Feira de Santana, Bahia, Brasil. ${ }^{2}$ Programa de Pós-Graduação em Botânica (UEFS). "cfnbio@gmail.com

RESUMO: Hyptis leucocephala e Hyptis platanifolia (Lamiaceae) são espécies aromáticas endêmicas do semiárido nordestino e possuem grande importância econômica devido ao seu potencial medicinal. $\mathrm{O}$ presente trabalho teve por objetivo obter o protocolo para $\mathrm{O}$ estabelecimento inicial in vitro das espécies $\mathrm{H}$. leucocephala e $\mathrm{H}$. platanifolia. O meio de cultura WPM promoveu a maior porcentagem de germinação (96,81\%) para H. leucocephala, porém não diferiu estatisticamente dos resultados obtidos no $\mathrm{MS}^{1} / 2$ na última semana de cultivo. Para a germinação de sementes de $H$. platanifolia, o MS $1 / 2$ foi o meio que proporcionou a maior porcentagem $(40,83 \%)$. O tipo de esterilização não interferiu na germinação in vitro para as duas espécies. Para a espécie $H$. platanifolia, quando se utilizou o fechamento dos tubos de ensaio com tampão de algodão, a hiperidricidade foi eliminada; porém, a porcentagem de germinação das sementes foi menor. Avaliando-se o tipo de meio de cultura no crescimento in vitro de $H$. leucocephala observou-se que este fator não influenciou no número de brotações, nem o comprimento de parte aérea e da matéria seca de raiz. O meio MS proporcionou incremento para o número de folhas, matéria seca da parte aérea, e comprimento da maior raiz, enquanto o meio $\mathrm{MS}^{1} / 2$ foi o que promoveu maior número de raízes. O meio de cultura ideal para a germinação de $H$. leucocephala e $H$. platanifolia foi o $M S^{1} 1 / 2$, podendo ser esterilizado com hipoclorito de sódio, enquanto que o MS foi o melhor meio de cultura para o crescimento in vitro de $H$. leucocephala.

Palavras-chave: Meios de cultura, Estabelecimento in vitro, Esterilização química, Crescimento in vitro.

ABSTRACT: In vitro germination of Hyptis leucocephala Mart. ex Benth. and Hyptis platanifolia Mart. ex Benth. The Hyptis leucocephala and Hyptis platanifolia (Lamiaceae) are aromatic species, endemic to the Brazilian Semiarid northeast, and they have great economic importance becaude of their pharmacological potential. This study aimed to obtain the protocol for the in vitro establishment of $\mathrm{H}$. leucocephala and $\mathrm{H}$. platanifolia plants. The WPM promoted higher germination percentage $(96.81 \%)$ for $H$. leucocephala, but there was no difference between the results obtained in $1 / 2 \mathrm{MS}$, in the last week of cultivation. For the germination of $H$. platanifolia, $1 / 2 \mathrm{MS}$ was the one that provided the highest percentage $(40.83 \%)$. The type of sterilization did not affect the in vitro germination of both species. For the $\mathrm{H}$. platanifolia species, when we closed the tubes with a cotton plug, hyperhydricity was eliminated, but the percentage of seed germination was the lowest one. Evaluating the type of culture medium on the in vitro growth of $\mathrm{H}$. leucocephala, it did not influence the number of shoots, length of shoot or root dry matter. The MS medium promoted an increase of the number of leaves, dry shoot and longest root length, and the $1 / 2 \mathrm{MS}$ medium was more suitable for root induction. The optimal culture medium for the germination of $H$. leucocephala and $H$. platanifolia is $1 / 2 \mathrm{MS}$, as it can be sterilized with sodium hypochlorite, while the MS was the best culture medium for the in vitro growth of $H$. leucocephala.

Keywords: Culture medium, in vitro establishment, Chemical sterilization, in vitro growth.

\section{INTRODUÇÃO}

Os componentes da biodiversidade podem fornecer uma ampla gama de produtos de importância econômica. Dentre eles, destacam-se os fitoterápicos e os fitofármacos, originados dos 
recursos genéticos vegetais, mais especificamente de plantas medicinais (Guerra \& Nodari, 2007), cuja demanda por espécies medicinais tem crescido consideravelmente nos últimos anos. De acordo com Giulietti \& Queiroz (2006), a região do semiárido possui alta diversidade da flora com potencial para o uso sustentável, incluindo alta proporção de espécies com compostos ativos. Na região já se obteve a descoberta de substâncias puras e a produção de semissintéticos com potencial de utilização em doenças que afetam a população da região.

Entre essas espécies vegetais produtoras de biocompostos, têm-se espécies aromáticas que possuem alto potencial antimicrobiano, como Hyptis leucocephala e H. platanifolia. O óleo essencial obtido das folhas de $H$. leucocephala possui atividade contra Bacillus cereus; Candida albicans e Staphylococcus aureus (Rodrigues, 2007), enquanto que o da espécie $H$. platanifolia, tem atividade frente à Salmonella choleraesuis; C. albicans e $S$. aureus (Moreira, 2006). O extrato metanólico das suas folhas e caules que também apresentaram atividade frente à Escherichia coli; C. albicans; S. aureus (Nobre, 2008). Resultados como esses podem ser promissores no sentido da descoberta de substâncias bioativas, uma vez que se tem observado o desenvolvimento da resistência microbiana às substâncias sintéticas já existentes.

Diante do elevado potencial fitoquímico e econômico dessas espécies para a população do semiárido, torna-se importante o desenvolvimento de pesquisas voltadas para a propagação e avaliação do potencial produtivo sob diferentes condições de cultivo. A propagação natural do gênero Hyptis se dá por sementes. Entretanto, a produção comercial de mudas por via sexual é limitada em virtude da dormência das sementes (Maia et al., 2008), além da sazonalidade na produção, com redução rápida da viabilidade (Oliveira et al., 2011). Para as duas espécies em estudo não existem relatos na literatura científica sobre a germinação das sementes e crescimento de mudas. Em trabalho realizado recentemente por Oliveira et al. (2011), verificou-se a viabilidade da propagação vegetativa via estaquia, demonstrando que a propagação assexual é um caminho viável a ser seguido para a propagação das mesmas.

Neste contexto, o uso de técnicas biotecnológicas, como a cultura de tecido vegetal, têm sido largamente utilizadas na propagação de plantas medicinais por possibilitar a produção massal eficiente de mudas micropropagadas. Esta técnica também contribui para preservar as populações naturais, pois para a obtenção do óleo essencial retira-se grande quantidade de plantas do ambiente natural, podendo ocasionar a extinção de espécies (Nepomuceno, 2012).

Para iniciar o processo de micropropagação é necessário estabelecer a espécie in vitro, ou seja, definir as melhores condições para a obtenção de material vegetal livre de contaminantes e com qualidade fisiológica adequada, de forma a viabilizar as demais etapas do cultivo in vitro. Para a maioria das espécies essa etapa tem sido o maior obstáculo, sobretudo, para aquelas com elevado número de tricomas nos caules e folhas, como é o caso das Lamiaceas, o que dificulta a assepsia inicial.

A origem do explante e o meio nutritivo onde este será cultivado são fatores que mais frequentemente determinam o sucesso da propagação in vitro. Diversas formulações de meio de cultura têm sido empregadas, as quais diferem entre si basicamente em relação à concentração dos sais. Entretanto, para cada tipo de explante, espécie e cultivar, o meio de cultura mais adequado e eficiente deve ser determinado experimentalmente, pois algumas espécies são acometidas por desordens morfofisiológicas provocadas, principalmente, pelas condições físicas e químicas do cultivo in vitro, ou devido às condições fisiológicas da espécie (Rezende et al., 2008).

Outra preocupação em relação ao cultivo in vitro é a redução de custos em laboratórios comerciais, pois a produção de mudas tem custo elevado devido, principalmente, às instalações necessárias e ao elevado gasto de energia para autoclavagem do meio de cultura, vidrarias, e manutenção das salas de crescimento. Estudos vêm sendo realizados com o intuito de substituir o processo de esterilização via autoclavagem por esterilização de menor custo (Teixeira et al., 2005). Várias espécies como Ananas comosus (Teixeira et al., 2006), Eucalyptus pellita (Teixeira et al., 2008), Pfaffia glomerata (Ribeiro et al., 2009), Anthurium anadraeanum (Cardoso, 2009), Gerbera jamesonii (Cardoso \& Teixeira da Silva, 2012) e Sequoia sempervirens (Ribeiro et al., 2011), já foram estabelecidas in vitro a partir da esterilização química, com resultados satisfatórios.

Assim, o presente trabalho teve por objetivo obter o protocolo para o estabelecimento inicial de plantas in vitro das espécies $\mathrm{H}$. leucocephala e $\mathrm{H}$. platanifolia.

\section{MATERIAL E MÉTODOS}

\section{Obtenção do material vegetal e local de realização dos experimentos}

As sementes de $H$. leucocephala e $H$. platanifolia foram obtidas da coleção de plantas aromáticas da Unidade Experimental Horto Florestal da Universidade Estadual de Feira de Santana 
(UEFS) e a identificação botânica foi realizada no herbário da UEFS, onde as exsicatas encontram-se depositadas (Vouchers número 131323 e 115466 , respectivamente). Os experimentos foram realizados no Laboratório de Cultura de Tecidos Vegetais (LCTV), pertencente à Unidade Experimental Horto Florestal/UEFS, localizado no município de Feira de Santana, região do semiárido da Bahia.

\section{Efeito do meio de cultura na germinação in vitro de $\boldsymbol{H}$. leucocephala e $\boldsymbol{H}$. platanifolia}

As sementes ficaram armazenadas em sacos de papel, os quais foram mantidos em frascos de vidro durante 90 dias. Após esse período, as sementes foram desinfestadas em álcool $70 \%$ por 1 minuto, seguido de solução de hipoclorito de sódio (Qboa ${ }^{\circledR}$ ) a 2,5\% de cloro ativo, acrescida de uma gota de detergente neutro por 15 minutos e, então, lavadas por quatro vezes em água destilada autoclavada. As mesmas foram inoculadas em meio de cultura MS (Murashige \& Skoog, 1962); em meio de cultura MS com a metade da concentração dos sais (MS1/2); em meio de cultura WPM (Lloyd \& McCown, 1980); em meio contendo apenas ágar, e em placa de Petri contendo papel germtest umedecido com água destilada autoclavada (Controle). Os meios de cultura foram solidificados com $0,7 \%$ de ágar e suplementados com $87,64 \mathrm{mM}$ de sacarose (exceto para o meio de cultura que foi composto apenas por ágar).

O delineamento experimental foi inteiramente casualizado, composto por cinco tratamentos (Meios de cultura: MS, MS $1 / 2$, WPM, ágar) e controle. Cada tratamento foi constituído por seis repetições e cada uma constou de quatro frascos onde foram inoculadas vinte sementes. Avaliou-se a porcentagem de germinação semanalmente durante um período de 15 dias para $H$. leucocephala e 40 dias para $H$. platanifolia.

Avaliação da eficiência da esterilização química do meio de cultura na germinação in vitro de $\boldsymbol{H}$. leucocephala e $\boldsymbol{H}$. platanifolia e crescimento in vitro de $\boldsymbol{H}$. platanifolia

As sementes recém-coletadas de $H$. leucocephala e H. platanifolia foram desinfestadas, como no item anterior, e inoculadas no meio de cultura MS $1 / 2$, suplementado com $87,64 \mathrm{mM}$ de sacarose e solidificado com $0,7 \%$ de ágar. $O$ meio de cultura foi esterilizado através de dois métodos: por autoclave (à $121^{\circ} \mathrm{C}$ por $15 \mathrm{~min}$ ) e por esterilização química utilizando-se o hipoclorito de sódio (Qboa $\left.{ }^{\circledR}\right)$ conforme metodologia descrita por Teixeira et al. (2006) com modificações.

A esterilização química iniciou-se com a lavagem da vidraria e tampas plásticas utilizadas no preparo do meio de cultura, sendo enxaguadas em água destilada, seguida de enxague em solução contendo 10 gotas de cloro ativo a $2 \%$ para $1 \mathrm{~L}$ de água destilada. Após a esterilização, as vidrarias foram armazenadas na bancada. Antes do uso, a vidraria e as tampas plásticas foram novamente enxaguadas em solução contendo $0,0003 \%$ de cloro ativo, sendo que os recipientes que acondicionaram o meio de cultura só foram enxaguados $15 \mathrm{~min}$ antes da distribuição do meio de cultura. A solução utilizada para preparar o meio de cultura conteve três gotas de cloro ativo a $2 \%$ para $1 \mathrm{~L}$ de água destilada. Após colocar todas as substâncias do meio de cultura, adicionou-se $0,0005 \%$ de cloro ativo e, depois de $15 \mathrm{~min}$, ajustou-se o $\mathrm{pH}$ para $5,7 \pm 0,1$ (utilizando-se $\mathrm{NaOH}$ ou $\mathrm{HCl} 0,1 \mathrm{~N}$ ). A distribuição do meio de cultura nos recipientes foi realizada em capela de fluxo laminar.

Para $H$. platanifolia foram utilizados diferentes tipos de fechamento dos tubos de ensaio [PVC; Tampão de algodão (TA) e Tampa plástica (TP)], totalizando quatro tratamentos: $1-\mathrm{PVC} /$ esterilização via autoclave; 2 - PVC/ esterilização química; 3 - TA/ esterilização química e 4 - TP/ esterilização química.

O delineamento experimental foi inteiramente casualizado. Para a espécie $H$. leucocephala, os tratamentos foram constituídos por doze repetições, sendo que cada uma constou de quatro frascos e com vinte sementes por frasco. Para H. platanifolia cada tratamento foi composto por dez repetições e a parcela experimental foi constituída por cinco tubos contendo uma semente por tubo de ensaio. Avaliou-se após 15 dias da inoculação a porcentagem de germinação para $H$. leucocephala e, após 30 dias, a porcentagem de germinação, o comprimento da parte aérea, o número de folhas, e a porcentagem de plantas hiperídricas para $H$. platanifolia.

\section{Avaliação do meio de cultura no crescimento in vitro de $H$. leucocephala \\ Utilizou-se como fonte de explante, o} segmento nodal de plantas estabelecidas em meio de cultura MS $1 / 2$, os quais foram inoculados em tubos de ensaio contendo diferentes meios de cultura: MS, MS $1 / 2$ e WPM. Os meios foram suplementados com $87,64 \mathrm{mM}$ de sacarose e solidificados com $0,7 \%$ de ágar.

O delineamento experimental utilizado foi inteiramente casualizado, constituído de três tratamentos (Meios de cultura: MS, MS $1 \frac{1}{2}$ e WPM). Os tratamentos foram compostos por dez repetições, sendo que cada repetição constou de oito unidades experimentais. Aos sessenta dias da inoculação foram avaliadas as seguintes variáveis: número de brotações por explante, número total de folhas e número de raízes, comprimento da maior brotação 
$(\mathrm{cm})$ e das raízes $(\mathrm{cm})$, matéria seca das brotações e das raízes $(\mathrm{mg})$.

\section{Condições experimentais e análises estatísticas}

$\mathrm{O} \mathrm{pH}$ do meio de cultura em todos os tratamentos testados foi ajustado para 5,7 \pm 0,1 (utilizando-se $\mathrm{NaOH}$ ou $\mathrm{HCl} 0,1 \mathrm{~N}$ ) antes da autoclavagem à temperatura de $121^{\circ} \mathrm{C}$ por 15 minutos, exceto para o meio de cultura esterilizado quimicamente, que seguiu a metodologia de Teixeira et al. (2006).

As culturas foram mantidas em sala de crescimento com temperatura de $25 \pm 3^{\circ} \mathrm{C}$, fotoperíodo de 16 horas, umidade relativa de $60 \%$ e radiação fotossintética ativa de $60 \mu \mathrm{mol} \mathrm{m} \mathrm{m}^{-2} \mathrm{~s}^{-1}$.

Os dados foram avaliados estatisticamente, mediante a análise de variância, testando-se as médias pelo Teste de Tukey. Os dados foram analisados usando o programa Sisvar (Ferreira, 2011).

\section{RESULTADOS E DISCUSSÃO}

\section{Efeito do meio de cultura na germinação in vitro de $\boldsymbol{H}$. leucocephala e $\boldsymbol{H}$. platanifolia \\ Observou-se efeito altamente significativo} $(p \leq 0,01)$ entre os meios de cultura para a porcentagem de germinação in vitro de $H$. leucocephala e de $H$. platanifolia durante o período de avaliação.

A germinação das sementes de $H$. leucocephala ocorreu em todos os meios de cultura testados, apresentando alta taxa de germinação, evidenciando que o tipo de meio de cultura não é um fator limitante para a germinação das sementes da referida espécie. Já na segunda semana, quando foi alcançada a estabilização da germinação, verificouse, a maior porcentagem de germinação quando as sementes foram inoculadas no meio WPM $(96,81 \%)$. No entanto, este resultado não diferiu estatisticamente dos resultados promovidos pela utilização do ágar, MS e MS $1 / 2$, superando o meio de cultivo contendo apenas água destilada (Controle), sendo que este apresentou resultado inferior em cerca de 22,70\% (Figura 1A).

Avaliando o comportamento germinativo para espécie $H$. platanifolia, também se observou que as sementes germinaram em todos os meios de cultura, porém a germinação foi mais lenta e apresentou porcentagem de germinação inferior a $H$. leucocephala. Ao final da quinta semana da inoculação das sementes, obteve-se a maior porcentagem de germinação $(40,83 \%)$ no meio de cultura MS $1 / 2$, sendo detectada diferença estatística em relação aos demais meios de cultura utilizados. O meio MS $1 / 2$ induziu aumento em torno de 2,5 vezes quando comparado ao meio de cultivo que continha apenas água destilada (Controle) (Figura 1B). Diante desses resultados, pode-se inferir que a diferença na concentração ou composição dos sais entre os meios de cultura testados parece ter afetado o processo germinativo das sementes de H. platanifolia. Resultados semelhantes foram observados para as espécies Vanda coerulea (Hossain et al., 2010) e Cymbidium giganteum (Roy et al., 2011).

Diante dos resultados apresentados para $\mathrm{H}$. leucocephala e $H$. platanifolia verificou-se aumento significativo na porcentagem de germinação quando as sementes foram inoculadas em um dos tipos de meio de cultura quando comparadas ao tratamento onde foi utilizada apenas água destilada (Controle), indicando que a maior disponibilidade de nutrientes favorece e/ou são necessários ao processo de germinação, além da sacarose, a qual está prontamente disponível para o crescimento, atuando como fonte de energia.

Embora em todos os meios de cultura tenha ocorrido alta taxa de germinação in vitro para $H$. leucocephala, em observações visuais verificou-se que as plantas no meio de cultura WPM e MS apresentaram a formação de "roseta" na base, seguido do alongamento de apenas um broto por roseta, enquanto as plantas provenientes da germinação no meio contendo apenas ágar não cresceram satisfatoriamente. As sementes que germinaram em meio $M S 1 / 2$ não formaram roseta na base da planta, alongando-se de forma normal. Já aquelas que germinaram em placa de Petri (água destilada), foram transferidas para meio de cultura, mas não sobreviveram.

Observando o crescimento das plantas de $H$. platanifolia verificou-se elevado índice de hiperidricidade nas plantas germinadas in vitro, independente do meio de cultivo. A hiperidricidade é uma desordem morfofisiológica que acomete algumas espécies propagadas in vitro, a qual é causada por diversos fatores que estão associados ao ambiente físico e químico do cultivo in vitro. Caracteriza-se por apresentar caules e folhas com aspecto vítreo, espesso e facilmente quebradiço. As alterações morfológicas e fisiológicas influenciam severamente os processos metabólicos e fisiológicos associados, principalmente, com a fotossíntese e a transpiração (Ziv, 1990; Hazarika, 2006).

Avaliação da eficiência da esterilização química do meio de cultura na germinação in vitro de $H$. leucocephala e $H$. platanifolia e crescimento in vitro de $\boldsymbol{H}$. platanifolia

No cultivo in vitro de $\mathrm{H}$. leucocephala não foi observado efeito significativo dos tipos de esterilização do meio de cultura para a variável 
porcentagem de germinação in vitro das sementes. Observou-se efeito altamente significativo $(p \leq 0,01)$ entre os diferentes tipos de fechamento dos tubos e da esterilização do meio de cultura para todas as variáveis analisadas no cultivo in vitro de $H$. platanifolia.

O tipo de esterilização do meio de cultura também não interferiu na germinação das sementes de $H$. platanifolia. A maior porcentagem de germinação ocorreu quando os tubos de ensaio foram fechados com PVC e o meio de cultura foi esterilizado com hipoclorito de sódio (92,50\%). Este resultado não diferiu estatisticamente dos resultados obtidos quando os tubos foram fechados com PVC e o meio foi esterilizado via autoclave ou, quando foi utilizado tampa plástica e o meio foi esterilizado quimicamente. Nestes dois casos a porcentagem de germinação foi de $74,17 \%$ e $71,33 \%$, respectivamente (Tabela 1 ), indicando que a concentração de hipoclorito de sódio utilizada não apresentou toxicidade às sementes desta espécie. Estes resultados estão de acordo com aqueles encontrados para Melocactus glaucescens em que o tipo de esterilização não interferiu na germinação das sementes (Resende, 2010).

A menor porcentagem de germinação foi observada quando se utilizou o fechamento dos tubos de ensaio com tampão de algodão/ esterilização química para a espécie $H$. platanifolia (Tabela 1). É possível que este valor inferior para a porcentagem de germinação tenha ocorrido devido à rápida evaporação de água do meio de cultura e, como o processo germinativo dessa espécie é mais lento, esse provável ressecamento tenha interferido na taxa de germinação, além de proporcionar redução do potencial osmótico do meio de cultura. Mesmo que no primeiro momento essas sementes tenham absorvido água, a possível restrição hídrica subsequente impediu que o processo germinativo continuasse em função da interrupção de processos metabólicos importantes, que depois da segunda fase da germinação (ativação do metabolismo), necessita de reabsorção de água.
Em relação à hiperidricidade, os resultados obtidos com a utilização de tubos com tampão de algodão combinado com a esterilização com hipoclorito de sódio, diferiram estatisticamente dos resultados obtidos nos demais tratamentos. Entretanto, não foi verificada a ocorrência dessa desordem morfofisiológica quando os tubos foram fechados com tampão de algodão associado à esterilização química. A maior taxa de hiperidricidade $(44,49 \%)$ ocorreu quando os tubos foram fechados com PVC e o meio esterilizado através da autoclave (Tabela 1).

No cultivo in vitro convencional se utiliza o PVC para o fechamento dos recipientes proporcionando alta umidade dentro dos frascos. Esta umidade aumenta a disponibilidade de água dentro dos recipientes, o que favorece a absorção excessiva de água pelos tecidos das plantas e, como consequência, pode conduzir a planta ao processo de hiperidricidade. Já a utilização do tampão de algodão reduz a umidade dentro dos tubos, contribuindo para o aumento do fluxo transpiratório da planta devido à promoção das trocas gasosas, além de reduzir e/ou reverter o processo de hiperidricidade. A esterilização química, também atuou como fator para a redução da hiperidricidade, provavelmente devido a maior consistência do meio de cultura em relação ao meio autoclavado, diminuindo assim a disponibilidade de água para as plantas.

Embora o uso do tampão de algodão tenha proporcionado a eliminação da hiperidricidade, é mais vantajoso utilizar o fechamento com PVC e esterilização química, já que a taxa de germinação foi superior $42,87 \%$ e a taxa de hiperidricidade foi baixa (Tabela 1), o que possibilita maior número de plantas para as etapas posteriores da micropropagação.

Analisando o comprimento da parte aérea verificou-se que a maior média foi obtida quando se utilizou tampa plástica/ esterilização química $(1,23 \mathrm{~cm})$. Porém, este resultado não diferiu estatisticamente dos resultados obtidos quando os tubos foram fechados com PVC associado à

TABELA 1. Porcentagem de germinação e de hiperidricidade de plantas de $H$. platanifolia submetidas a diferentes tipos de fechamento dos tubos de ensaio e esterilização do meio de cultura. Feira de Santana, 2012.

\begin{tabular}{llc}
\hline Fechamento/ Esterilização & Germinação (\%) & Hiperidricidade (\%) \\
\hline PVC/ Autoclave & 74,17 a & $44,49 \mathrm{a}$ \\
PVC/ Química & $92,50 \mathrm{a}$ & $6,00 \mathrm{bc}$ \\
Tampão de algodão/ Química & $39,66 \mathrm{~b}$ & $0,00 \mathrm{c}$ \\
Tampa plástica/ Química & $71,33 \mathrm{a}$ & $28,83 \mathrm{ab}$
\end{tabular}

Médias seguidas pela mesma letra na coluna não diferem entre si estatisticamente ao nível de $5 \%$ de probabilidade pelo teste de Tukey.

Rev. Bras. PI. Med., Campinas, v.16, n.4, p.886-895, 2014. 
esterilização química (Tabela 2). Para o número de folhas, a maior média foi observada para o tratamento PVC/ esterilização por autoclave $(3,86)$, o qual não diferiu estatisticamente dos tratamentos PVC/ esterilização química e tampa plástica/ esterilização química (Tabela 2). Resultados semelhantes foram encontrados para Eucalyptus pellita (Teixeira et al., 2008) e Sequoia sempervirens (Ribeiro et al., 2011), em que foi observado aumento no crescimento da parte aérea quando o meio nutritivo foi esterilizado com hipoclorito de sódio.

Esses resultados corroboram aqueles reportados por Teixeira et al. (2006; 2008) sobre a viabilidade do uso do hipoclorito de sódio, em baixas concentrações como agente esterilizante do meio de cultura de tecidos vegetais, pois não apresentou efeito fitotóxico para as duas espécies em estudo e, além disso, não foi verificado a ocorrência de contaminação da cultura.

\section{Avaliação do meio de cultura no crescimento in vitro de $\mathrm{H}$. leucocephala}

Observou-se efeito significativo $(p \leq 0,05)$ para número total de folhas e matéria seca de parte aérea e altamente significativo $(p \leq 0,01)$ para número e comprimento de raiz.

A maior média para número total de folhas por explante $(83,30)$ foi obtida em meio de cultura MS, a qual diferiu significativamente dos resultados obtidos com a utilização do MS $1 / 2$ e do meio WPM, que apresentaram, por sua vez, as menores médias $(60,93 ; 58,78)$ (Figura 2A). Resultados semelhantes foram observados por Rezende et al. (2008) no cultivo in vitro de Coffea arabica, em que o meio de cultura MS promoveu incrementos no número de folhas ao comparar com os meios testados (WPM, Knudson e White), assim como ocorreu para a espécie Passiflora laurifolia (Faria et al., 2007). Por outro lado, resultados diferentes foram relatados para Olea europaea, uma vez que, os meios WPM e o MO (Rugini, 1984) foram mais eficientes para a produção de folhas desta espécie (Donini et al.,
2008). Em Calendula officinalis o tipo de meio de cultura utilizado não influenciou no número de folhas (Bertoni et al., 2006).

Comportamento semelhante ao observado para número de folhas foi obtido para a matéria seca da parte aérea, sendo possível observar que os resultados obtidos a partir do meio de cultura MS diferiram estatisticamente dos demais, proporcionando incrementos em torno de $38,75 \%$ em relação aos meios de cultura WPM e MS $1 / 2$, que apresentaram médias de 47,07 e $45,79 \mathrm{mg}$, respectivamente (Figura 2B). Resultados semelhantes foram obtidos para Baccharis tridentata (Kajiki \& Shepherd, 2006) e Mentha sp (Tonietto et al., 2008).

As médias superiores para as variáveis analisadas proporcionadas pelo meio de cultivo MS para $H$. leucocephala, podem estar associadas ao enriquecimento nutricional que este meio possui, o que lhe confere maior força iônica, suprindo os requerimentos nutricionais que a espécie em estudo necessita. De acordo com Rocha et al. (2007), o meio nutritivo MS possui maior concentração de nitrogênio total $(60 \mu \mathrm{M})$ do que o WPM $(14,7 \mu \mathrm{M})$, nas

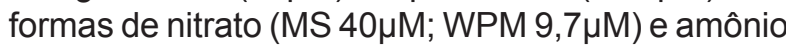

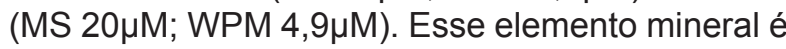
considerado como um dos mais importantes para o crescimento e desenvolvimento do vegetal, já que está envolvido na síntese de aminoácidos e proteínas (Sodek, 2004; George \& Klerk, 2008). Segundo Caldas et al. (1998) o nitrogênio tem efeito marcante sobre o crescimento e desenvolvimento de culturas de tecidos vegetais. As formas nas quais o nitrogênio (nitrato e amônio) está disponível no meio de cultura são rapidamente assimiláveis e apresentam funções que são primordiais para o metabolismo celular, tal como a manutenção do balanço iônico intra e extracelular (George \& Klerk, 2008).

Analisando o sistema radicular, verificou-se maior número de raízes $(11,01)$ quando os explantes foram cultivados em meio de cultura $\mathrm{MS} 1 / 2$, diferindo estatisticamente dos resultados obtidos para os

TABELA 2. Médias do comprimento da parte aérea (CPA) e número de folhas (NF) de plantas de H. platanifolia submetidas a diferentes tipos de fechamento dos tubos de ensaio e esterilização do meio de cultura. Feira de Santana, 2012.

\begin{tabular}{lll}
\hline Fechamento/ Esterilização & CPA (cm) & NF \\
\hline PVC/ Autoclave & $0,94 \mathrm{~b}$ & $3,86 \mathrm{a}$ \\
PVC/ Química & $1,08 \mathrm{ab}$ & $2,68 \mathrm{a}$ \\
Tampão de algodão/ Química & $0,47 \mathrm{c}$ & $0,79 \mathrm{~b}$ \\
Tampa plástica/ Química & $1,23 \mathrm{a}$ & $3,49 \mathrm{a}$ \\
\hline
\end{tabular}

Médias seguidas pela mesma letra na coluna não diferem entre si estatisticamente ao nível de 5\% de probabilidade pelo teste de Tukey.

Rev. Bras. PI. Med., Campinas, v.16, n.4, p.886-895, 2014. 


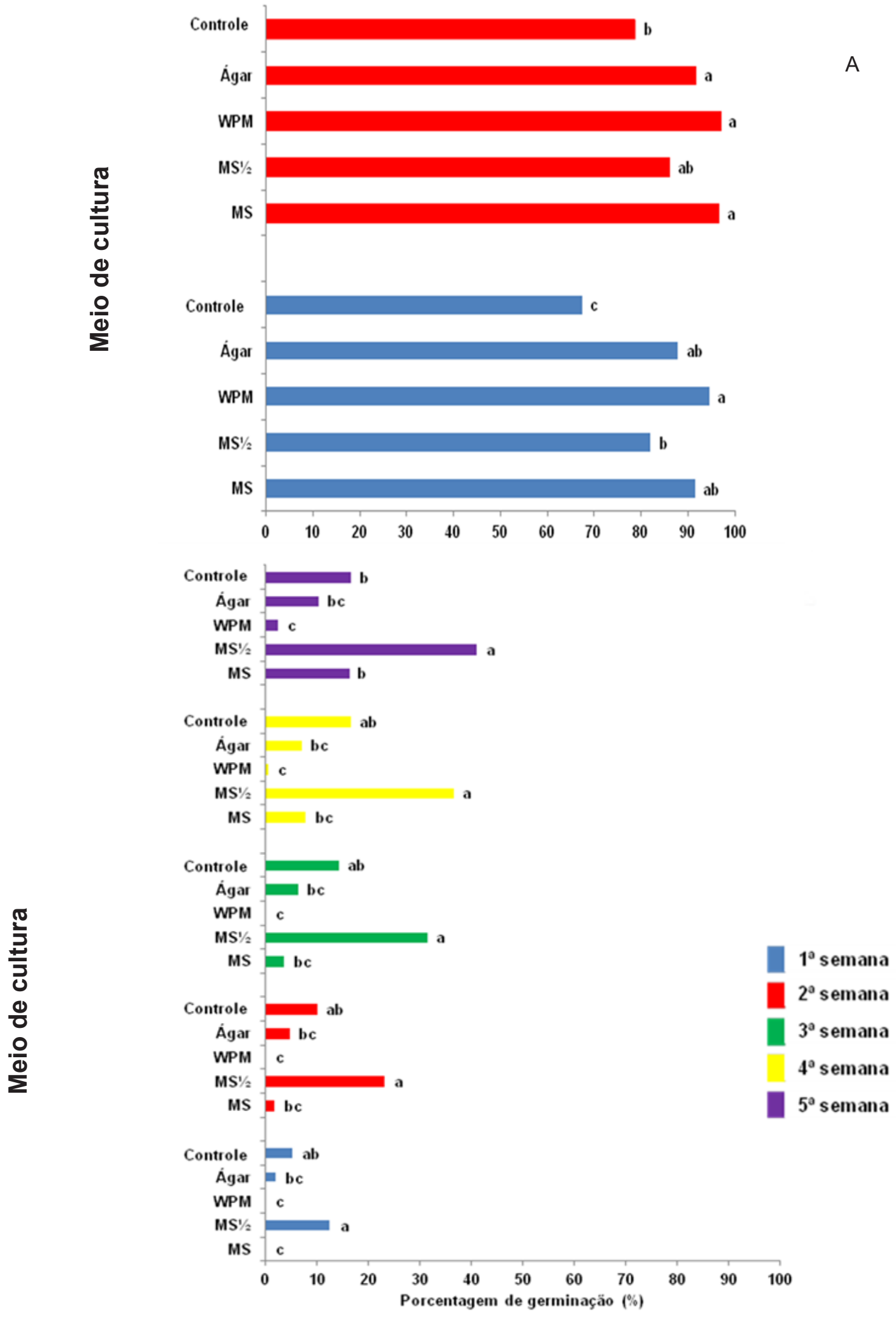

FIGURA 1. Porcentagem de germinação in vitro de $H$. leucocephala (A) e $H$. platanifolia (B) submetidas a diferentes tipos de meio de cultura. Avaliação semanal: $1^{\mathrm{a}}$ semana; $2^{\mathrm{a}}$ semana; $3^{\mathrm{a}}$ semana; $4^{\mathrm{a}}$ semana; $5^{\mathrm{a}}$ semana. Médias seguidas pela mesma letra não diferem entre si estatisticamente ao nível de 5\% de probabilidade pelo teste de Tukey. Feira de Santana, 2012. 
A

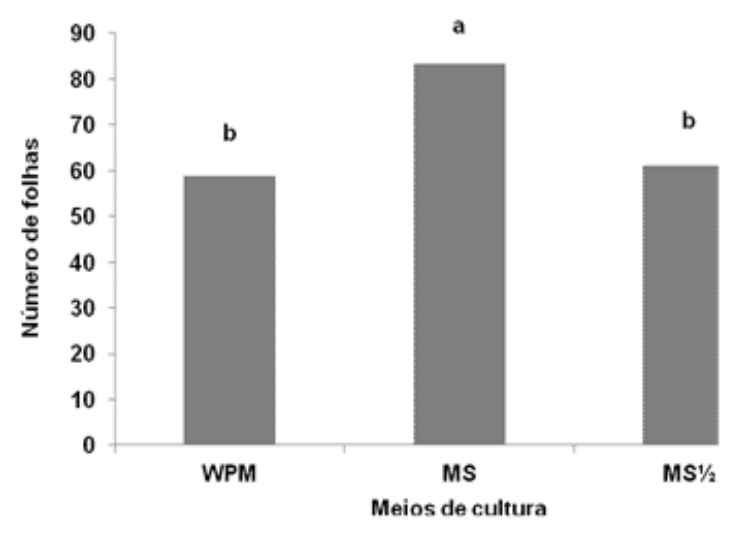

C

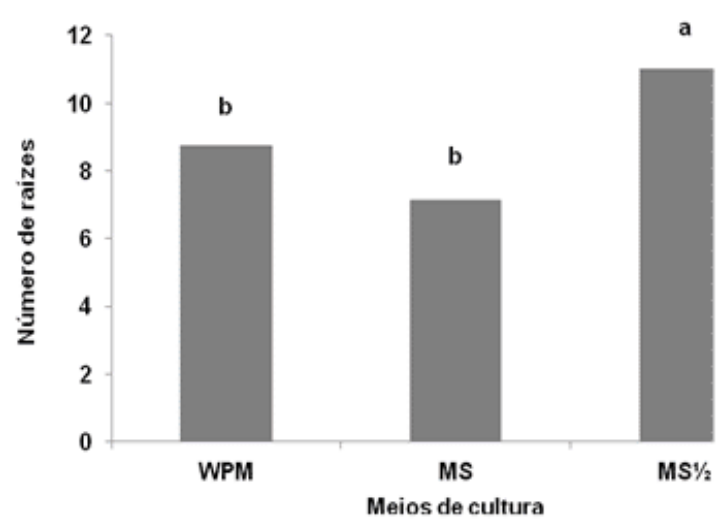

B

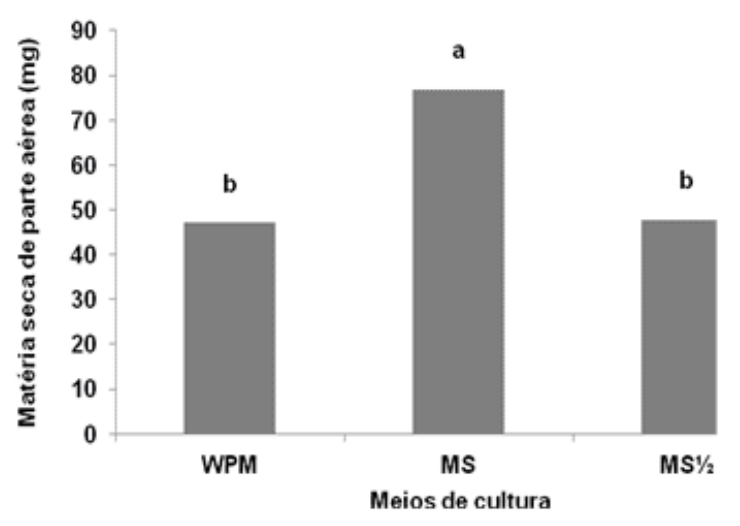

D

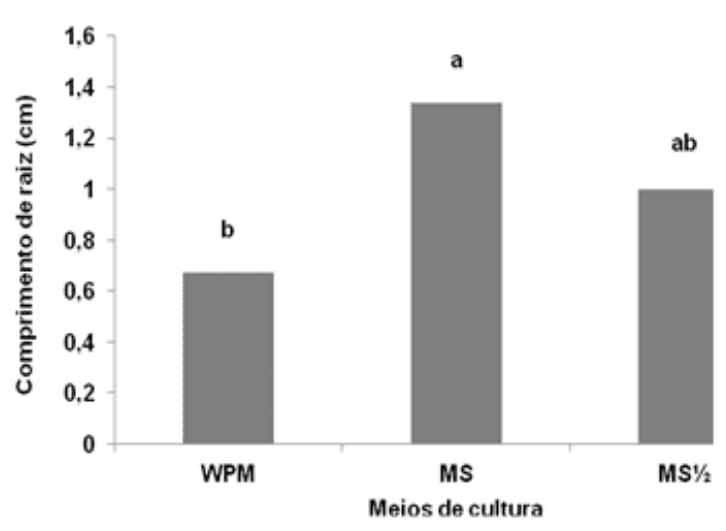

FIGURA 2. Médias do número total de folhas por explante $(A)$, matéria seca da parte aérea $(B)$, número de raízes (C) e comprimento da raiz (D) obtidos em de $H$. leucocephala estabelecidas a diferentes meios de cultura. Médias seguidas pela mesma letra na coluna não diferem entre si estatisticamente ao nível de $5 \%$ de probabilidade pelo teste de Tukey. Feira de Santana, 2012.

outros dois tipos de meio de cultura utilizados (Figura 2C). Resultados semelhantes foram reportados por Bertoni et al. (2006) para Calendula officinalis, que verificaram maior número de raízes quando utilizaram o meio de cultura MS $1 / 2$ e também em Passiflora edulis f. edulis (Faria et al., 2007). Contudo, resultados diferentes foram encontrados para Lippia sidoides (Costa et al., 2007) e Luehea divaricata (Flôres et al., 2011) que apresentaram enraizamento in vitro mais eficiente em o meio de cultura WPM. Já para Passiflora laurifolia o meio de cultura MS proporcionou maior número de raízes, enquanto que, para Passiflora giberti, o tipo de meio não influenciou no número de raízes (Faria et al., 2007), assim como verificado para Prunus cerasifera (Chaves et al., 2006).

Os resultados encontrados para número de raízes de $H$. leucocephala, bem como para outras espécies, em meio MS $1 / 2$ ou WPM provavelmente se deu devido à concentração reduzida dos sais, que, de acordo com Assis \& Teixeira (1998), estimula a emissão e alongamento de raízes.

Para o comprimento das raízes, quando os explantes foram cultivados em meio de cultura MS, verificou-se aumento de duas vezes no comprimento quando comparados aos cultivados em meio WPM. Contudo, os resultados promovidos pelo meio de cultura MS não diferiram estatisticamente dos obtidos a partir do meio de cultura MS $1 / 2$ (Figura 2D). Efeito semelhante ocorreu para Mentha sp., que indicaram maior comprimento da raiz no meio de cultura mais concentrado, o MS (Tonietto et al., 2008). Entretanto, resultados diferentes foram observados por Chaves et al. (2006) nas culturas de Prunus cerasifera, em que o tipo de meio de cultura não influenciou no crescimento das raízes.

Segundo Faria et al. (2007) e Flôres et al. (2011), as espécies possuem características únicas, determinadas por fatores genéticos, levando a diferentes respostas in vitro e, portanto, 
as condições necessárias para o cultivo in vitro são diferenciadas e dependentes da espécie.

\section{CONCLUSÕES}

O meio de cultura que deve ser utilizado para a germinação in vitro de sementes de $H$. leucocephala e $H$. platanifolia é o MS $1 / 2$. A esterilização química do meio de cultura pode ser utilizada para o estabelecimento in vitro de $\mathrm{H}$. leucocephala e $\mathrm{H}$. platanifolia. O meio MS pode ser utilizado para o crescimento in vitro de $H$. leucocephala.

\section{REFERÊNCIA}

ASSIS, T.F.; TEIXEIRA, S.L. Enraizamento de lenhosas. In: TORRES, A.C.; CALDAS, L.S.; BUSO, J.A. Cultura de tecidos e transformação genética de plantas. Brasília, EMBRAPA-SPI/ EMBRAPA-CNPH, v.1, 1998. 261-296p.

BERTONI, B.W. et al. Micropropagação de Calendula officinalis. Revista Brasileira de Plantas Medicinais, v.8, n.2, p.48-54, 2006.

CALDAS, L.S.; HARIDASAN, P.; FERREIRA, M.E. Meios nutritivos. In: TORRES, A.C.; CALDAS, L.S.; BUSO, J.A. Cultura de tecidos e transformação genética de plantas. Brasília, EMBRAPA-SPI/ EMBRAPA-CNPH, v.1, 1998. 87-132p.

CARDOSO, J.C. Esterilização química de meio de cultura no cultivo in vitro de antúrio. Pesquisa Agropecuária Brasileira, v.44, n.7, p.785-788, 2009.

CARDOSO, J.C.; TEIXEIRA da SILVA, J.A. Micropropagation of gerbera using chlorine dioxide $\left(\mathrm{ClO}_{2}\right)$ to sterilize the culture medium. In Vitro Cellular and Developmental Biology - Plant, v.48, p.362-368, 2012.

CASTRO, R.D.; HILHORST, H.W. Embebição e reativação do metabolismo. In: Ferreira, A.G.;Borghetti, F. (Orgs.). Germinação: do básico ao aplicado. Porto Alegre: Artmed. 2004, 149-162p.

CHAVES, A.C. et al. Efeito do meio de cultura e concentrações de auxinas no enraizamento in vitro de Prunus cerasifera CV. MR. S. 1/8. Plant Cell Culture \& Micropropagation, v.2, n.1, p.43-47, 2006.

COSTA, A.S. et al. Estabelecimento de alecrim-pimenta in vitro. Horticultura Brasileira, v.25, n.1, p.68-72, 2007.

DONINI, L.P. et al. Estabelecimento in vitro de oliveira cv. "Arbequina" para início da micropropagação. Ciência Rural, v.38, n.6, p.1769-1772, 2008.

FARIA, G.A. et al. Meio de cultura e tipo de explante no estabelecimento in vitro de espécies de maracujazeiro. Bragantia, v.66, n.4, p.535-543, 2007.

FERREIRA, D.F. Sisvar: a computer statistical analysis system. Ciência e Agrotecnologia, v.35, n.6, p.10391042, 2011.

FLÔRES, A.V. et al. Estabelecimento e multiplicação in vitro de Luehea divaricata Mart. \& Zucc. Ciência Florestal, v. 21, n.1, p.175-182, 2011.

GEORGE, E.F.; KLERK, G-J. The Components of Plant
Tissue Culture Media I: Macro- and Micro-Nutrients. In: GEORGE, E.F.; HALL, M.A.; KLERK, G-J. Plant Propagation by Tissue culture. Dordrecht: Springer, $3^{\text {rd }}$ Edition, v.1, 2008. 65-114p.

GUERRA, M.P.; NODARI, R.O. Biodiversidade: aspectos biológicos, geográficos, legais e éticos. In: SIMÕES, C.M.O.; SCHENKEL, E.P.; MELLO, J.C.P; MENTZ, L.A.; PETROVICK, P.R. (Orgs.) Farmacognosia: da planta ao medicamento. $6^{a}$ ed., Porto Alegre: Editora da UFRGS; Florianópolis: Editora da UFSC, 2007.13-28p.

GIULIETTI, A.M.; QUEIROZ, L.P. Plantas da Caatinga: perfil botânico, fitoquímica e atividade biológica. Recife, Associação Plantas do Nordeste, v.4, 2006. 497p.

HAZARIKA, B.N. Morpho-physiological disorders in vitro culture of plants. Scientia Horticulturae, v.108, p.105120, 2006.

HOSSAIN, M.M. et al. Seed germination and tissue culture of Cymbidium giganteum Wall. ex Lindl. Scientia Horticulturae, v.123, p.479-487, 2010.

KAJIKI, F.O.; SHEPHERD, S.L.K. Micropropagação da espécie nativa Baccharis tridentata Vahl. (Asteraceae). Revista Brasileira de Plantas Medicinais, v. 8, n.2, p.42-47, 2006.

LLOYD, G.; McCOWN, B. Use of microculture for production and improvement of Rhododendronn ssp. HortScience, v.15, n.3, p.416-420, 1980.

MAIA, S.S.S. et al. Germinação de sementes de Hyptis suaveolens (L.) Poit. (Lamiaceae) em função da luz e temperatura. Caatinga, v. 21, n.4, p.212-218, 2008.

MOREIRA, J.S. Variabilidade sazonal da composição química e atividade antimicrobiana do óleo essencial extraído de Hyptis platanifolia. 2006. Trabalho de Conclusão de Curso. (Graduação em Ciências Farmacêuticas) - Universidade Estadual de Feira de Santana, Feira de Santana.

MURASHIGE, T.; SKOOG, F. A revised medium for a rapid growth and bioassays with tabacco tissue cultures. Physiologia Plantarum, n.15, p.493-497, 1962.

NEPOMUCENO, C.F. Propagação e Conservação in vitro de Martianthus leucocephalus. 2012. 180p. Doutorado (Doutorado em Botânica) - Universidade Estadual de Feira de Santana, Feira de Santana.

NOBRE, I.K.C. Atividade Antimicrobiana de Extrato Bruto de Espécies do Gênero Hyptis da região do Semi- Árido Baiano. 2008. Dissertação (Mestrado em Programa de Pós-graduação em Biotecnologia) Universidade Estadual de Feira de Santana, Feira de Santana.

OLIVEIRA, L.M. et al. Propagação vegetativa de Hyptis leucocephala Mart. ex Benth. e Hyptis platanifolia Mart. ex Benth. (Lamiaceae). Revista Brasileira de Plantas Medicinais, v.13, n.1, p.73-78, 2011.

RESENDE, S.V. Micropropagação e conservação in vitro de Melocactus glaucescens Buining \& Brederoo e Melocactus paucispinus G. Heimen \& R. Paul (Cactaceae), espécies endêmicas da Bahia e ameaçadas de extinção. 2010. Tese - Programa de Pós-Graduação em Botânica - Universidade Estadual de Feira de Santana, Feira de Santana.

REZENDE, J.C. et al. Influência do meio de cultura e concentração de agar no crescimento e desenvolvimento de plântulas de café oriundas da embriogênese somática 
direta. Scientia Agraria, v.9, n.1, p.21-26, 2008.

RIBEIRO, J.M. et al. Calogênese em explantes de Pfaffia glomerata (Spreng.) Pedersen cultivados em meio nutritivo esterilizado com hipoclorito de sódio. Revista Ceres, v.56, n.5, p.537-541. 2009.

RIBEIRO, J.M. et al. Cultivo in vitro de Sequoia sempervirens L. em meio de nutritivo esterilizado com hipoclorito de sódio. Ciência Florestal, v.21, n.1, p.7782, 2011.

ROCHA, S.C. et al. Micropropagação de Cabralea canjerana. Revista Árvore, v.31, n.1, p.43-50, 2007.

RODRIGUES, O.S. Óleo essencial de Hyptis leucocephala Mart. Ex Benth: composição química e atividade antimicrobiana. 2007. Trabalho de Conclusão de Curso. (Graduação em Ciências Farmacêuticas) - Universidade Estadual de Feira de Santana, Feira de Santana.

ROY, A.R. et al. Asymbiotic seed germination, mass propagation and seedling development of Vanda coerulea Griff ex. Lindl. (Blue Vanda): An in vitro protocol for an endangered orchid. Scientia Horticulturae, n.128, p.325-331, 2011.

RUGINI, E. In vitro propagation of some olive (Olea europaea sativa L.) cultivars with different rootability, and medium development using analytical data from developing shoots and embryos. Scientia Horticulturae, v.24, n.2, p.123-134, 1984.

SODEK, L. Metabolismo do nitrogênio. In: KERBAUY, G.B. Fisiologia Vegetal. Ed: Guanabara Koogan, Rio de Janeiro-RJ, 2004. 452p.

TEIXEIRA, S. L. et al. Cultura de tecidos vegetais, pela combinação de esterilizantes e forno microondas. Revista Ceres. v.52, n.301, p.343-349, 2005.

TEIXEIRA, S.L. et al. Influence of $\mathrm{NaClO}$ on nutrient medium sterilization and on pineapple (Ananas comosus cv Smooth cayenne) behavior. Plant Cell Tissue Organ Culture, n.86, p.375-378, 2006.

TEIXEIRA, S.L. et al. Utilização de hipoclorito de sódio na esterilização de meio de cultura para a multiplicação in vitro de Eucalyptus pellita L. Ciência Florestal, v.18, n.2, p.185-191, 2008.

TONIETTO, S.M.; PERINI, C.B.; TONIETTO, A. Concentrações e composição do meio de Murashige \& Skoog na micropropagação da menta. Plant Cell Culture \& Micropropagation, n. 4, v.1, p.42-47, 2008.

ZIV, M. Vitrification: morphological and physiological disorders of in vitro plants. In: DEBERGH, P.C.; ZIMMERMAN, R.H. Micropropagation - Technology and Application. Kluwer Academic Publishers, p.4569, 1990. 